\title{
New International Reports Editor and Managing Editor
}

We are pleased to announce the election of Dr. Winnie Wong-Ng of the National Institute of Standards and Technology (NIST) as International Reports Editor, and the appointment of Ms. Shannon Mattaboni of the International Centre for Diffraction Data (ICDD) as Managing Editor for Powder Diffraction.

\section{International Reports Editor}

Dr. Wong-Ng received a B.S. degree from the Chinese University of Hong Kong, with a major in Chemistry and a minor in Physics; and a Ph.D. degree in Inorganic Chemistry from Louisiana State University. Upon graduation, she worked at the University of Toronto as a research associate and lecturer. After moving back to the United States, she joined JCPDS-ICDD as a critical review scientist and $\mathrm{x}$-ray crystallographer. in 1983, she joined the National Bureau of Standards (now called the National Institute of Standards and Technology) as a member of the JCPDS associateship program. She became a member of the scientific staff of the Ceramics Division of NIST in 1988.

Her main research areas at NIST are phase equilibria, $\mathrm{x}$-ray crystallography, and crystal chemistry of technologically important materials, in particular, high-temperature superconductors. Her research interests in the x-ray diffraction area include powder and single-crystal diffractometry. She is presently involved in the development of a ruby sphere standard (NIST SRM 1990) for the alignment of single-crystal diffractometers. She is also an ICDD Grants-in-aid recipient working on the preparation of standard reference patterns for the Powder Diffraction File.

Dr. Wong-Ng is a prolific author and has published over 200 scientific articles including technical papers, book chapters, edited books, and meeting reports. Among them, about 30 technical papers and 10 meeting reports were published in Powder Diffraction.

She is also very active in the x-ray community. She served as a local chairperson for the 1998 Annual Meeting of the American Crystallographic Association at Washington, DC and has been the chairperson of the Ceramics Subcommittee of ICDD since 1994.

The International Report section of Powder Diffraction is devoted to disseminating current information on activities of interest to the $\mathrm{x}$-ray and related communities. Topics of interest include meeting reports; book reviews; short descriptions of computer programs; new products and activities of any organizations which pertain to $x$-ray and related analyses; calendar of meetings, courses, and workshops.

For the International Reports section, we also have four regional correspondents: Dr. Tony Raftery, Dr. Hideo Toraya, Dr. Ludwik Gorski, and Dr. Norberto Masciocchi to report on scientific meetings and community activities in Australia/New Zealand, Asia, Eastern and Western Europe, respectively. Reports on computer programs are edited by Dr. Robert Dinnebier. Calendar of meetings, courses, and workshops are compiled by Dr. Donald Petersen. Their postal details can be found in this issue, and correspondence with Dr. Dinnebier should be addressed to Dr. Robert Dinnebier, University of Bayreuth, Laboratory of Crystallography, Bayreuth, D-95440, Germany (telephone: 49-921553880, fax: 49-921-553770 and e-mail: robert.dinnebier@uni-bayreuth.de).

\section{Managing Editor}

Ms. Shannon Mattaboni joined the ICDD staff in 1995 and has served as the Desktop Publishing Coordinator in the Publishing Department since 1996. As the Managing Editor, she will take on additional responsibilities. She will be responsible for nontechnical matter for Powder Diffraction and for communication with the journal publisher, the American Institute of Physics (AIP). All final manuscripts after being formally accepted by the Editor-in-Chief will be forwarded to her to be prepared for records and for final transfer to AIP for processing and printing. Should the Managing Editor finds that she needs more information or better prepared materials (such as figures and references) from the authors in order to proceed, she will get in touch with the corresponding authors directly.

Finally, many thanks to Elizabeth Bond for having edited the International Reports section from 1998 to 1999 and to Mary (Mickey) Rossi for having served as Managing Editor from 1996 to 1999.

Ting C. Huang Editor-in-Chief 